Dokuz Eylül Üniversitesi-Mühendislik Fakültesi

Fen ve Mühendislik Dergisi

Cilt 20, Sayı 60, Eylül, 2018
Dokuz Eylul University-Faculty of Engineering Journal of Science and Engineering Volume 20, Issue 60, September, 2018

DOI: $10.21205 /$ deufmd.2018206080

\title{
XRF, FT-IR Spektroskopik Yöntemleri ve SEM Yöntemi Kullanılarak Üç Dental Kompozit Örneklerin İncelenmesi
}

\author{
Ünal ŞAHINNCİ ${ }^{1}$, Sema ÖZTÜRK YILDIRIM ${ }^{* 2}$ \\ 1Erciyes Üniversitesi, Fen Fakültesi, Fizik Bölümü, 38039, Kayseri. \\ $2^{2}$ Erciyes Üniversitesi, Fen Fakültesi, Fizik Bölümü, 38039, Kayseri.
} (ORCID: 0000-0001-5962-5337)

(Alınış / Received: 06.03.2018, Kabul / Accepted: 04.06.2018, Online Yayınlanma / Published Online: 15.09.2018)

Anahtar Kelimeler Dental Kompozit, XRF,

FT-IR, SEM.

Özet: Günümüzde doğal dişin görünümünü taklit edebilen ve estetik olması nedeniyle dental kompozitlerin dental restorasyon malzemesi olarak kullanımı oldukça yaygındır.

$\mathrm{Bu}$ çalışmada diş hekimlerinin çoğunlukla kullandığı üç farklı dental kompozit rezinin örneklerinin yapısal parametrelerinin tespiti spektroskopik analiz yöntemleri kullanılarak yapılmıştır. XIşını Floresans Spektrometresi (XRF), Fourier Dönüşümlü Infrared Spektrofotometresi (FT-IR) ve Taramalı Elektron Mikroskobu (SEM) yöntemi ile yapılan element analizlerinde rezin örneklerinin yapısında bulunan bileșikler ve elementler tespit edilmiștir. Bileşikler 6-heptenoik asit, 2-metilbütirik asit, etilen oksit, propiyonik asit, 5-metil 3-heksanon, linoleik asit, 1naftalenasetik asit, 4-hidroksi 4-metil 2-pentanon, trikloroasetonitril, benzil etil keton, 3-mercaptopropionik asit, oleik asit, 4-metil 2-pentanon, erüsik asit, deoksikolik asit'dir. Elemetler ise $\mathrm{Si}, \mathrm{Zr}, \mathrm{Hf}, \mathrm{Na}, \mathrm{Al}, \mathrm{Ca}, \mathrm{S}, \mathrm{Ti}, \mathrm{Fe}, \mathrm{K}, \mathrm{Y}, \mathrm{Ba}, \mathrm{P}, \mathrm{Cl}, \mathrm{Sr}, \mathrm{F}$, Zn'dir. Fiziksel olarak yapılan basma çekme testi sonucunda örneklerin maksimum gerilme, elastik uzama, maksimum kuvvet aralığı ve maksimum yüzde uzama miktarları: 10982.9$12867.1 \mathrm{~N} / \mathrm{mm}^{2} ; \quad 0,00827-0.05214 \mathrm{~mm} ; \quad 6987.00-13650.2 \mathrm{~N}$ ve 77.4643-160.420 olarak tespit edilmiștir.

The Investigation of Three Dental Composite Samples by Using XRF, FTIR Spectroscopic Methods and SEM Method

\section{Keywords}

Dental Composite

XRF,

FT-IR,

SEM.

\begin{abstract}
Dental composites are widely-used dental restoration materials that they are both aesthetical and they can easily simulate the natural appearance of teeth. In this study, determination of structural parameters of three different types of dental composite resin samples, which are widely used by dentists, was done by using spectroscopic analysis methods. Compounds and elements in the structure of resin samples were determined through X-Ray Fluorescent Spectrometer (XRF), Fourier Transformational Infrared Spectrometer (FT-IR) and Scanning Electron Microscope (SEM) methods. the compounds are
\end{abstract}


Ü. ŞAHINCII, S. ÖZTÜRK YILDIRIM/ XRF, FT-IR Spektroskopik Yöntemleri ve SEM Yöntemi Kullanılarak Üç Dental Kompozit Örneklerin İncelenmesi

6-heptenoicacid, 2-metilbutyricacid, ethyleneoxidepressure, propionicacid, 5-metil 3-hexanone, linoleicacid, 1napthylaceticacid, 4-hydroxy 4-metil 2-pentanone, trichloroacetonitrile, benzyl ethyl ketone, 3mercaptopropionicacid, oleicacid, 4-metil 2-pentanone, erucicacid, deoxycholicacid and, the elements are $\mathrm{Si}, \mathrm{Zr}, \mathrm{Hf}, \mathrm{Na}, \mathrm{Al}$, $\mathrm{Ca}, \mathrm{S}, \mathrm{Ti}, \mathrm{Fe}, \mathrm{K}, \mathrm{Y}, \mathrm{Ba}, \mathrm{P}, \mathrm{Cl}, \mathrm{Sr}, \mathrm{F}, \mathrm{Zn}$. As a result of CompressiveTensile Strength Test, stress, elastic strain, ultimate strength range and maximum percentage elongation levels were determined as $10982.9-12867.1 \mathrm{~N} / \mathrm{mm} 2 ; 0,00827-0.05214 \mathrm{~mm}$; 6987.00-13650.2N and 77.4643-160.420.

*Sorumlu yazar: ozturk@erciyes.edu.tr

\section{Giriş}

Çalışmamızda diş hekimlerinin dolgu maddesi olarak kullandığı farklı firmalara ait, piyasada oldukça fazla rağbet gören üç farklı firmaya ait kompozit rezinlerin spektroskopik analizleri yapılmıștır. Numunelerin aynı zamanda fiziksel parametre testleri yapılarak dayanıklılık parametreleri tespit edilmiştir.

Dişhekimliğinde kullanılan ilk kompozit rezin 1960 yılında üretilmiştir [1].

Dental kompozitler organik bir yapı içerisinde belirli oranlarda inorganik partiküllerin ilavesi ve bu karışımın katkı maddeleri ile polimerizasyonu ile oluşur. $\mathrm{Bu}$ karıșım mekanik bir karıșımdır. Dental kompozitler özelliklerini bu iki fazın özelliklerinden ve kompozitin bileşime katılma oranlarından alırlar. Üçüncü faz olarak da interfasiyal faz sayılabilir. $\mathrm{Bu}$ faz bağlama veya birleştirici ajan olarak adlandırılır. Bu fazda kompozit dolgu maddelerine silan adı verilen organik silisyum bileșiği ilave edilir. Silan adı verilen bileşiğin görevi organik partiküller ile organik matris arasında bir bağ oluşturmaktır [2].

1970 yllarında işıkla polimerize olan kompozit rezinler geliştirilmeye başlanmıştır. Işıkla polimerize olan kompozit rezinlerin aşınma dirençlerinin ve renk stabilitesi gibi özelliklerinin kendiliğinden polimerize olan kompozit rezinlere oranla daha iyi olduğu gösterilmiştir [1].

Kompozit rezin materyalin aşınma direnci, mikro sertlik ve bükülme dayanımı gibi fiziksel veya mekanik özelliklerini araștırmak amacıyla değişik çalışmalara literatürde rastlanmaktadır [3].

Kompozit rezinlerin formülasyonunda yenilikler yapılarak fiziksel ve mekanik özellikleri geliştirilebilir. Bunun için kompozit rezinleri olușturan inorganik dolgu maddelerin element ve bileşik içerikleri değiştirebilinir ya da element ve bileşik oranları değiştirilebilir.

Dental kompozit rezin materyalleri organik rezin matriks ve inorganik doldurucular olmak üzere iki kısımdan oluşmaktadır. Dental kompozit rezinlerin organik matriks fazını oluşturmak için Bisphenol A glycidyl methacrylate (bisGMA) veya urethane dimethacrylate gibi bileşikler kullanılır [1]. Yüksek viskoziteli Bis-GMA'nın viskozitesini düşürmek için daha düşük viskoziteli triethyleneglycol dimethacrylate (TEGDMA) ve ethyleneglycol dimethacrylate (EGDMA) monomerlerini ilave edilir. Ayrıca düşük viskoziteye sahip manomer olarak de urethane dimethacrilate (UDMA)' da kullanılabilir [4]. Bis-GMA; Birçok kompozit rezinin monomer yapısında bulunan Bis-GMA bisfenol A ile glisidil metakrilatın reaksiyona girmesiyle 


\section{Ü. ȘAHINCII, S. ÖZTÜRK YILDIRIM/ XRF, FT-IR Spektroskopik Yöntemleri ve SEM Yöntemi Kullanılarak}

Üç Dental Kompozit Örneklerin İncelenmesi

veya bisfenol A'nın glisidil eteri ve metakrilik asitin reaksiyona girmesiyle elde edilebilir. [5]. TEG-DMA; kompozit rezinlere vizkoziteyi artırmak için eklenenir. Bis-GMA'ya oranla daha küçük ve daha esnek yapıdadır. Bundan dolayı TEG-DMA'nın kullanıldığı kompozit rezinlerde esneklik artarken asınma direnci düșer [6]. UDMA; Düşük vizkoziteye sahip olan UDMA, Bis GMA' ya göre daha kırılgan ve polimerizasyon büzülmesi daha fazladır. İnorganik kompozit rezinlerde ise farklı şekil, boyut ve kimyasal bileşiklerden oluşan doldurucular kullanılmaktadır. Kompozit rezinlerin fiziksel ve mekanik özelliklerini inoroganik doldurucular belirler. Kompozit rezinlerin içine katılan dolduruculanın miktarı arttıkça mekanik özellikleri artar. İnorganik oldurucular kompozit materyalin isısal genleşme katsayısı ve polimerizasyon büzülmesini azaltır, radyo opaziteyi sağlar, estetik sonuçları güçlendirir [7]. Boroslikat ve lityum aliminyum silkatlar en sik kullanılan dolduruculardır. Kuartzın yerini radyoopak olan baryum, stronsiyum, çinko, aliminyum veya zirkonyum gibi ağır metal partikülleri almıştır [8]. Kompozit rezinler içerisindeki doldurucu partikül oranları, doldurucu içindeki ağırlıkları ve hacimleri ile belirlenir. Kompozit rezinlerin fiziksel özelliklerinin belirlenmesinde kompozitin içerisindeki doldurucu miktarı belirleyicidir. Kompozit içerisindeki doldurucu miktarı arttıkça daha iyi özelliklere sahip kompozit elde edilir. Daha fazla oranda doldurucu miktarına sahip dental kompozitlerde su emilim miktarı, ısısal genleşme katsayısı ve polimerizasyon büzülmesi azalırken elastik modülü, çekme dayanımı ve kırılma dayanımı $\operatorname{artar}[9]$.

Kırılma mukaveti yüksek, sıvı emme özelliği düşük, aşınma dayanımı yüksek, renk stabilitesi yüksek olan dental kompozit üretimi oldukça önemlidir.
Dental kompozitlerin bileşik ve element içeriklerinin bilinmesi fiziksel ve kimyasal özelliklerinin geliştirilmesi açısından oldukça önemlidir. Dental kompozitlerin fiziksel ve mekanik özelliklerini artırmak amacıyla aşınma direnci, bükülme dayanımı ve yüzey sertliği gibi özellikleri araștırılmıştır. Nanoteknoloji kullanarak 0,1-100 nm boyutunda materyaller üretilmiştir [10]. Polimerizasyon büzülmesinde azalma, bükülme dayanımı ve kırılma dayanımında artma gibi özelliklerin sağlanması için dental kompozitlerin yapısında yüksek oranlarda doldurucu bulunmalıdır [11]. Dental kompozitlerin organik matriks ve inorganik dolgu materyallerinin birleştirilmesini sağlayan maddeye silan denir. İki fazın birbirine bağlanması için kullanılır [12]. Dental kompozitlerin mekanik özelliklerinin partikül büyüklüğü ile ilişkisini açıklamak için kırılma sertliği, sıkışma dayanımı ve aşınma dayanımı gibi birçok çalışma yapılmıştır [13].

Kompozit türleri partikül büyüklügününe göre de sinıflandırılmaktadır. Megafil kompozitler: $\quad 50-100 \mu \mathrm{m}$ boyutunda doldurucu partikül içerir. Makrofil Kompozitler: 1-10 $\mu \mathrm{m}$ boyutunda doldurucu partikül içerir. Minifil Kompozitler: $\quad 0,1-1 \quad \mu \mathrm{m}$ boyutunda doldurucu partikül içerir. Radyoopasite özelliği vardır aşınma direnci fazladır. Mikrofil Kompozitler: $\quad 0,01-0,1 \mu \mathrm{m}$ boyutunda doldurucu partikül içerir. Pürüssüz yüzeyler elde edilebilir ve radyoopak değildir [14]. Hibrit kompozitler: $\quad 0,04 \mu \mathrm{m}$ ve $1-5 \mu \mathrm{m}$ boyutunda farklı doldurucu partiküller içerir. Ortalama partikül büyüklüğü genellikle $0,6 \mu \mathrm{m}$ 'dir. Radyoopak olan hibrit kompozitlerin Fiziksel özellikleri genel olarak geleneksel kompozitlerle mikrofil kompozitlerin arasında olduğu söylenebilir [15]. Nanofil Kompozitler: 5$10 \mathrm{~nm}$ boyutunda farklı doldurucu partiküller içerir [16]. 
Ü. ŞAHINCİ, S. ÖZTÜRK YILDIRIM/ XRF, FT-IR Spektroskopik Yöntemleri ve SEM Yöntemi Kullanılarak Üç Dental Kompozit Örneklerin İncelenmesi

\section{Materyal ve Metot}

Hazırlanan numuneler onbeş gün (15) boyunca gün ışı̆̆ında polimerize olmaları için bekletildi. Polimerize olan numunelerin X-ışını floresans spektrumları elde edilmesinde PANalytical AXIOS ADVANCED, fourier dönüşümlü infrared spektrumları PERKIN ELMER 400 FT-IR/FT-FIR SPECTROMETER SPOTLIGHT 400 IMAGING SYSTEM ve taramalı elektron mikroskobu görüntülerinin alınmasında ise LEO 440 COMPUTER CONTROLLED DIGITAL cihazları kullanıldı. Basma dayanımı testi için özel $3 \mathrm{~mm}$ çapında ve $6 \mathrm{~mm}$ derinliğinde silindirik paslanmaz çelik kaplar hazırlandı. Kaplara konan numuneler gün ışığında onbeş gün (15) polimerize olmaları için bekletildi. Kenarlarındaki fazlalıklar zımpara ile temizlenerek SHIMADZU AG-XD $50 \mathrm{kN}$ cihazında basma çekme dayanımı ölçüldü. ISO 7500/1, ASTM E4, DIN51221 standartlarına göre $50 \mathrm{kN}$ ile $50 \mathrm{~N}$ aralığında $\pm \% 0.1$ hassasiyetli okuma aralığı sahip olan cihazdan alınan veriler analiz edildi.

\section{Bulgular}

İlk olarak dental kompozit numunelerin XRF spektroskopik analiz yöntemi kullanılarak rezinlerin yapısını oluşturan elementler tespit edilmiştir. Şekil 1(a/b)-3'de numunelere ait XRF element analiz grafiği verilmiştir. Grafikten de görüleceği gibi, $\mathrm{Si}, \mathrm{Zr}$, Hf, $\mathrm{Na}, \mathrm{Al}, \mathrm{Ca}, \mathrm{S}, \mathrm{Ti}$, $\mathrm{Fe}, \mathrm{K}, \mathrm{Y}, \mathrm{Ba}, \mathrm{P}, \mathrm{Cl}, \mathrm{Sr}, \mathrm{F}, \mathrm{Zn}$ tespit edilmiştir.

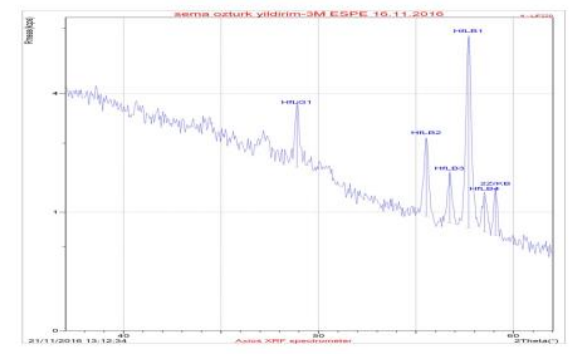

Şekil 1.a Birinci numuneye ait XRF grafiği.

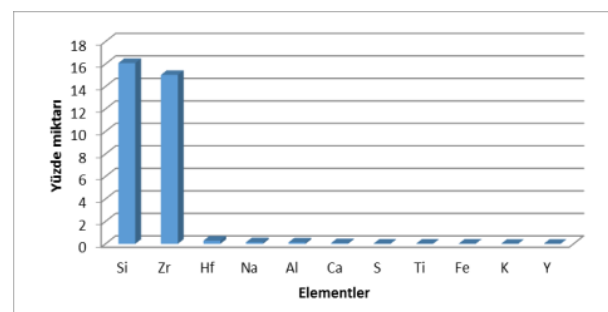

Şekil 1.b Birinci numuneye ait XRF element analiz grafiği.

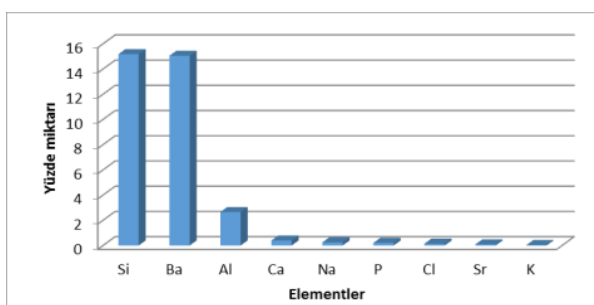

Şekil 2. İkinci numuneye ait XRF element analiz grafiği.

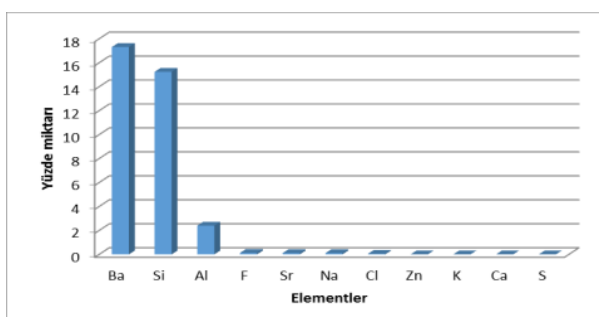

Şekil 3. Üçüncü numuneye ait XRF element analiz grafiği.

Kompozit rezinlerin yapısını oluşturan elementler için IBM-SPSS-22 istatistik programı kullanılarak normalite testi yapılmıştır (SPSS for Windows Inc. Version 22. Chicago, Illinois). Normalite testi sonucunda bazı elementlerin normal dağılım gösterdiği bazı elementlerin ise normal dağılım göstermediği görülmüştür (Tablo 1). 
Ü. ŞAHINCİ, S. ÖZTÜRK YILDIRIM/ XRF, FT-IR Spektroskopik Yöntemleri ve SEM Yöntemi Kullanılarak Üç Dental Kompozit Örneklerin İncelenmesi

Tablo 1. Numunelerde bulunan elementlerin Shapiro-Wilk normalite testi.

\begin{tabular}{|c|c|c|c|}
\hline \multirow{2}{*}{} & \multicolumn{3}{|c|}{ Shapiro-Wilk Testi } \\
\cline { 2 - 4 } & Statistic & $\mathrm{df}$ & $\mathrm{p}<0.05$ \\
\hline $\mathrm{Si}$ & 0.808 & 3 & 0.135 \\
$\mathrm{Zr}$ & 0.750 & 3 & 0.000 \\
$\mathrm{Hf}$ & 0.750 & 3 & 0.000 \\
$\mathrm{Na}$ & 0.915 & 3 & 0.435 \\
$\mathrm{Al}$ & 0.823 & 3 & 0.170 \\
$\mathrm{Ca}$ & 0.853 & 3 & 0.249 \\
$\mathrm{~S}$ & 0.972 & 3 & 0.679 \\
$\mathrm{Ti}$ & 0.750 & 3 & 0.000 \\
$\mathrm{Fe}$ & 0.750 & 3 & 0.000 \\
$\mathrm{~K}$ & 0.887 & 3 & 0.344 \\
$\mathrm{Y}$ & 0.750 & 3 & 0.000 \\
$\mathrm{Ba}$ & 0.846 & 3 & 0.231 \\
$\mathrm{P}$ & 0.750 & 3 & 0.000 \\
$\mathrm{Cl}$ & 0.988 & 3 & 0.793 \\
$\mathrm{Sr}$ & 0.924 & 3 & 0.468 \\
$\mathrm{~F}$ & 0.750 & 3 & 0.000 \\
$\mathrm{Zn}$ & 0.750 & 3 & 0.000 \\
\hline
\end{tabular}

Dental kompozit rezinlerin FTIR spektroskopik analiz yöntemi kullanılarak analizleri yapılmıştır. Yapılan analiz sonucunda herbir kompozit rezinin yapısını olușturan bileşikler Tablo 2' de verilmiștir. Ayrıca numunelerin basma çekme dayanımı ölçülmüştür. Uygulanan maksimum kuvvet ve maksimum gerilme değerleri Tablo 3' de yer almaktadır.

Tablo 2. Numunelerin FTIR analizi sonucunda elde edilen bileşik içerikleri.

$\begin{array}{ccc}\text { Numune 1 } & \text { Numune 2 } & \text { Numune 3 } \\ \text { 6-heptenoik asit } & \text { 6-heptenoik asit } & \text { 6-heptenoik asit } \\ \text { 2-metilbütirik asit } & \text { 2-metilbütirik asit } & \text { 2-metilbütirik asit } \\ \text { etilen oksit } & \text { 4-metil 2-pentanon } & \text { erüsik asit } \\ \text { propiyonik asit } & \text { propiyonik asit } & \text { propiyonik asit } \\ \text { 5-metil 3-heksanon } & \text { 5-metil 3-heksanon } & \text { 5-metil 3-heksanon } \\ \text { linoleik asit } & \text { linoleik asit } & \text { linoleik asit } \\ \text { 1-naftalenasetik asit } & \text { oleik asit } & \text { 4-metil 2-pentanon } \\ \text { 4-hidroksi 4-metil 2- } & \text { 4-hidroksi 4-metil 2- } & \text { 4-hidroksi 4-metil 2- } \\ \text { pentanon } & \text { pentanon } & \text { pentanon } \\ \text { trikloroasetonitril } & \text { benzil etil keton } & \text { deoksikolik asit } \\ \text { deoksikolik asit } & \text { 3-mercaptopropionik asit } & \end{array}$


Ü. ŞAHINCİ, S. ÖZTÜRK YILDIRIM/ XRF, FT-IR Spektroskopik Yöntemleri ve SEM Yöntemi Kullanılarak Üç Dental Kompozit Örneklerin İncelenmesi

Tablo 3. Numunelerin basma çekme testi ölçüm değerleri.

\begin{tabular}{lcccc} 
& $\begin{array}{c}\text { Maksimum Gerilme } \\
{\left[\mathrm{N} / \mathrm{mm}^{2}\right]}\end{array}$ & $\begin{array}{c}\text { Maksimum Uzama } \\
{[\%]}\end{array}$ & $\begin{array}{c}\text { Elastik Uzama } \\
{[\mathrm{mm}]}\end{array}$ & $\begin{array}{c}\text { Maksimum kuvvet } \\
{[\mathrm{N}]}\end{array}$ \\
\hline Numune 1 & 10982,9 & 77,4643 & 0,00827 & 6987 \\
Numune 2 & 21456,7 & 160,42 & 0,05214 & 13650,2 \\
Numune 3 & 12867,1 & 100,045 & 0,05129 & 8185,68
\end{tabular}

Kompozit rezinlerinlere ait farklı büyütme ölçeklerinde SEM görüntüleri alınarak, yüzey görüntüleri incelenmiștir (Şekil 4-6).

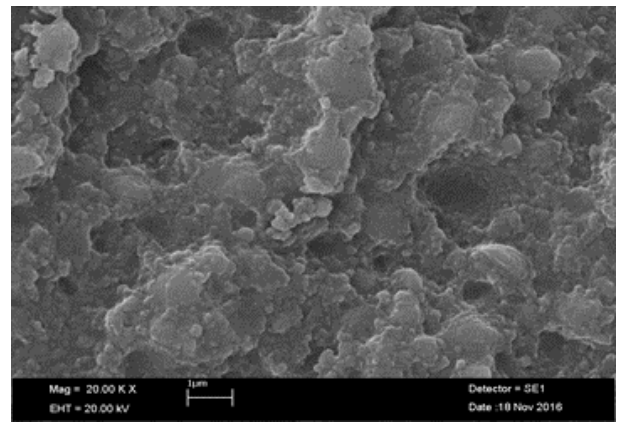

Şekil 4. Birinci numuneye ait SEM görüntüsü.

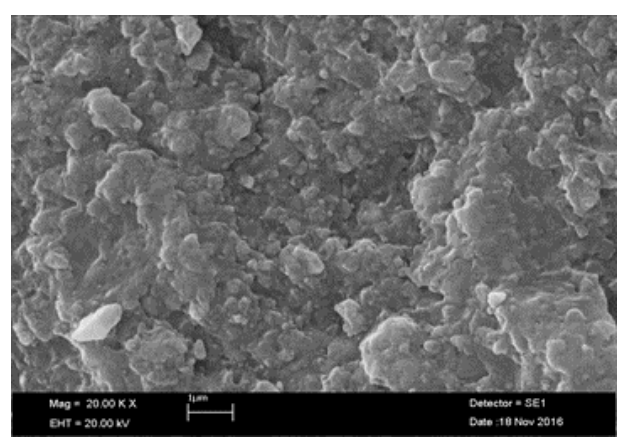

Şekil 5. İkinci numuneye ait SEM görüntüsü.

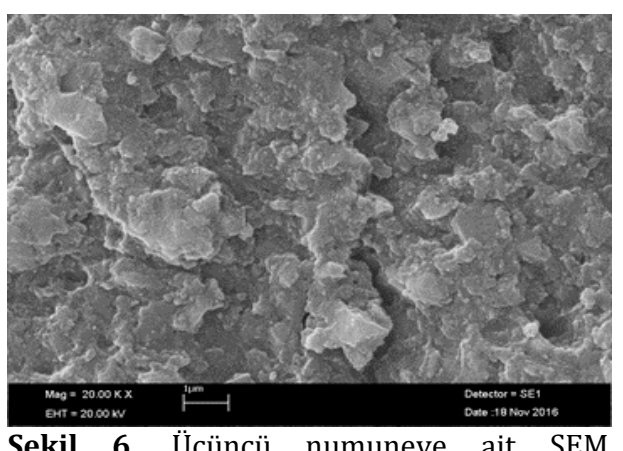

Şekil 6. Üçüncü numuneye ait SEM görüntüsü.

\section{Tartışma ve Sonuç}

Bu çalışmada farklı spektroskopik analiz yöntemleri kullanılarak dental kompozit rezin örneklerin element ve bileșik analizleri yapılmıştır.

X-Işını floresans spektroskopi yöntemi kullanılarak elde edilen analiz sonuçlarına göre numunelerde farklı elementler tespit edilmiștir. İlk numunede tespit ettiğimiz elementler; $\mathrm{Si}, \mathrm{Zr}, \mathrm{Hf}, \mathrm{Na}, \mathrm{Al}, \mathrm{Ca}, \mathrm{S}, \mathrm{Ti}, \mathrm{Fe}, \mathrm{K}, \mathrm{Y}$ bulunurken ikinci numunede; $\mathrm{Si}, \mathrm{Ba}, \mathrm{Al}$, $\mathrm{Ca}, \mathrm{Na}, \mathrm{P}, \mathrm{Cl}, \mathrm{Sr}, \mathrm{K}$ ve üçüncü numunede ise; $\mathrm{Ba}, \mathrm{Si}, \mathrm{Al}, \mathrm{F}, \mathrm{Sr}, \mathrm{Na}, \mathrm{Cl}, \mathrm{Zn}, \mathrm{K}, \mathrm{Ca}, \mathrm{S}$ elementleri tespit edilmiştir. Sonuçlar incelendiğinde $\mathrm{Si}, \mathrm{Na}, \mathrm{Al}, \mathrm{Ca}, \mathrm{K}$ herbir kompozitin yapısında yer almaktadır. $\mathrm{Zr}, \mathrm{Hf}, \mathrm{S}, \mathrm{Ti}, \mathrm{Fe}, \mathrm{Y}, \mathrm{Ba}, \mathrm{P}, \mathrm{Cl}, \mathrm{Sr}, \mathrm{F}, \mathrm{Zn}$ elementleri ise numunelerde değişim göstermektedir. Bunun yanı sıra numunelerde ortak bulunan elementler kendi rezin içeriğinde farklı yüzdelerde bulunduğu gözlenmiștir. İlk numunede

(\%) Si 16.076> Zr 15.022> Hf 0.281> Na $0.137>\mathrm{Al} 0.127>\mathrm{Ca} 0.063>\mathrm{S} 0.017>\mathrm{Ti}$ $0.014>\mathrm{Fe} 0.014>\mathrm{K} 0.008>$ Y 0.002 
Ü. ŞAHINCİ, S. ÖZTÜRK YILDIRIM/ XRF, FT-IR Spektroskopik Yöntemleri ve SEM Yöntemi Kullanılarak Üç Dental Kompozit Örneklerin İncelenmesi

oranında bulunurken ikinci numunede (\%) Si 15.171> Ba 15,045> Al 2.651> Ca $0.393>\mathrm{Na} 0.247>\mathrm{P} 0.204>\mathrm{Cl} 0.138>\mathrm{Sr}$ $0.083>$ K 0.029 oranında bulunmuştur. Üçüncü numunede ise bu oran (\%) Ba 17.315> Si 15.242> Al 2.404> F 0.125> Sr $0.111>\mathrm{Na} 0.103>\mathrm{Cl} 0.056>\mathrm{Zn}$ $0.013>$ K 0.012> Ca 0.009> S 0.006 şeklindedir.

Fourier Dönüşümlü Infrared Spektroskopisi analizleri sonucunda dental kompozit rezinleri oluşturan bileşik yapıları tespit edildi. İlk numuneyi oluşturan bileșikler 6heptenoik asit, 2-metilbütirik asit, etilen oksit, propiyonik asit, 5-metil 3heksanon linoleik asit, 1-naftalenasetik asit, 4-hidroksi 4-metil 2-pentanon, trikloroasetonitril, deoksikolik asit bileşikleridir. İkinci numuneyi oluşturan bileşikler olarak 6-heptenoik asit, 2metilbütirik asit, 4-metil 2-pentanon, propiyonik asit, 5-metil 3-heksanon, linoleik asit, oleik asit, 4-hidroksi 4metil 2-pentanon, benzil etil keton, 3mercaptopropionik asit bulunmuştur. Üçüncü numuneyi oluşturan bileşikler ise 6-heptenoik asit, 2-metilbütirik asit, erüsik asit, propiyonik asit, 5-metil 3heksanon, linoleik asit, 4-metil 2pentanon, 4-hidroksi 4-metil 2pentanon, oleik asit, deoksikolik asit tespit edilmiştir. Bazı bileşikler (etilen oksit, 4-metil 2-pentanon, erüsik asit, 1naftalenasetik asit, oleik asit, trikloroasetonitril, benzil etil keton, deoksikolik asit, 3-3-mercaptopropionik asit) bazı numunelerde bulunmazken bazı bileşikler ise (6-heptenoik asit, 2-2metilbütirik asit, propiyonik asit, 5metil 3-heksanon, linoleik asit, 4hidroksi 4-metil 2-pentanon) ortak üç numunede de bulunmuştur.

Taramalı elektron mikroskobu kullanılarak her bir numunenin yüzey görüntüleri farklı büyütme ölçeği kullanılarak yüzey fotoğrafları alındı. Elde edilen görüntüler son derece dikkatli bir şekilde incelendi. Görüntülerde dental kompozit rezinlerin yüzey yapılarının da birbirlerinden anlamlı şekilde farklı olduğunu tespit edildi.

Fiziksel olarak yapılan basma çekme testi sonucunda örneklerin maksimum gerilme, elastik uzama, maksimum kuvvet aralığı ve maksimum yüzde uzama miktarlarl: 10982.9$12867.1 \mathrm{~N} / \mathrm{mm} 2 ; \quad 0,00827-0.05214 \mathrm{~mm}$; $6987.00-13650.2 \mathrm{~N}$ ve $77.4643-160.420$ olarak tespit edilmiştir. $\mathrm{Bu}$ değerler literatür ile uyumludur [17-18].

Basma çekme testinde elde edilen verilerin farklı alması element ve bileşik içeriklerinin farklı olmasından kaynaklanmaktadır. Ayrıca SEM yüzey görüntülerinin farklı olması basma çekme testinin verilerinin farklı olmasını desteklemektedir.

$\mathrm{Bu}$ alanda geniş ve kapsamlı olarak yapılan ilk çalışmalardan biridir ve daha sonraki çalışmalara ışık tutacaktır.

\section{Kaynakça}

[1] Baum L, Phillips RW, Lund MR. 1985. Textbook of Operative Dentistry. Tooth Colored Restratives. 2th. Edition, 206s.

[2] Bayırlı G, Şirin T. 1982. Konservatif Diş tedavisi. Dünya Tıp Kitapevi Ltd. Şti. ss161-184, İstanbul.

[3] Gladys S, Van MB, Braem M, Lambrechts P, Vanherle G. 1997. Comparative Physico-Mechanical Characterization of New Hybrid Restorative Materials With Conventional Glass-İonomer And Resin Composite Restorative Materials. J Dent Res, Ss 883-894.

[4] Peutzfeldt A. 1997. Resin Composites İn Dentistry: The Monomer Systems. Eur J Oral Sci. ss97-116.

[5] Craig RG. 1989. Restorative Dental Materials 8th Ed. St. Louis. 
Ü. ŞAHINCİ, S. ÖZTÜRK YILDIRIM/ XRF, FT-IR Spektroskopik Yöntemleri ve SEM Yöntemi Kullanılarak Üç Dental Kompozit Örneklerin İncelenmesi

[6] Parker S, Braden M. 1998. Water Absorption Of Methacrylate Soft Lining Materials. Biomaterials, ss591.

[7] Labella R, Lambrechts P, Van Meerbeek B, Vanherle G. 1999. Polymerization Shrinkage And Elasticity Of Flowable Composites And Filled Adhesives. Dent Mater, Ss 37-128.

[8] Moszner N, Salz U. 2001. New Developments Of Polymeric Dental Composites. Prog.Polym.Sci, ss 535-576.

[9] Ikejima I, Nomoto R, Mccabe JF. 2003. Shear Punch Strength And Flexural Strength of Model Composites With Varying Filler Volume Fraction, Particle Size And Silanation. Dent Mater, Ss 11-206.

[10] Beun S, Glorieux T, Devaux J, Vreven J, Leloup G. 2007. Characterization of Nanofilled Compared To Universal And Microfilled Composites. Dent Mater. Ss 9-51.

[11] Mitra SB, WU D, Holmes BN. 2003. An Application Of Nanotechnology İn Advanced Dental Materials. J Am Dent Assoc, ss90-1382.

[12] Pu Z, Mark JE, Jethmalani JM, Ford WT. 1997. Effects Of Dispersion And Aggregation of Silica İn The Reinforcement Of Poly(Methylacrylate) Elastomers. Chem Mater, ss7-2442.

[13] Turssi CP, Ferracane JL, Vogel K. 2005. Filler features and their effects on wear and degree of conversion of particulate dental resin composites. Biomaterials, ss4932-4937.

[14] Sturdevant M, Roberson TM, Heyman HO, Sturdevant JR. 2000.The Art And Science Of Operative dentistry, 3rd ed. StLouis, :Mosby.

[15] O’Brien WJ. 2002. Dental Materials And Their Selection. Polymeric
Restorative Metarials. 3th Edition, Canada, ss113-116.

[16] Venhoven BAM, de Gee AJ, Werner A, Davidson CL. 1996. Influence of filler parameters on the mechanical coherence of dental restorative resin composites. Biomaterials, ss40-735.

[17] Rothmunda L, Hea X, Van KL, Helmut Schweikl L, Hellwig E, Carell T, Reinhar H, Reichl F-X, Högga C. 2005. Effect of Opalescence $囚$ bleaching gels on theelution of dental composite components. Biomaterials. 26, ss 1713-1719.

[18] Hervás García A, Martínez Lozano M A, Vila JC, Barjau Escribano A, Fos Galve P. 2006. Composite resins. A review of the materials and clinical indications. Med Oral Patol Oral Cir Bucal 11, E215-20. 